\title{
Opposed-flow Flame Spread Over Solid Fuels in Microgravity: the Effect of Confined Spaces
}

\section{Shuangfeng Wang, Jun Hu, Yuan Xiao, Tan Ren \& Feng Zhu}

Microgravity Science and Technology An International Journal for Microgravity and Space Exploration Related Research

ISSN 0938-0108

Volume 27

Number 5

Microgravity Sci. Technol. (2015) 27:329-336

DOI 10.1007/s12217-015-9419-z

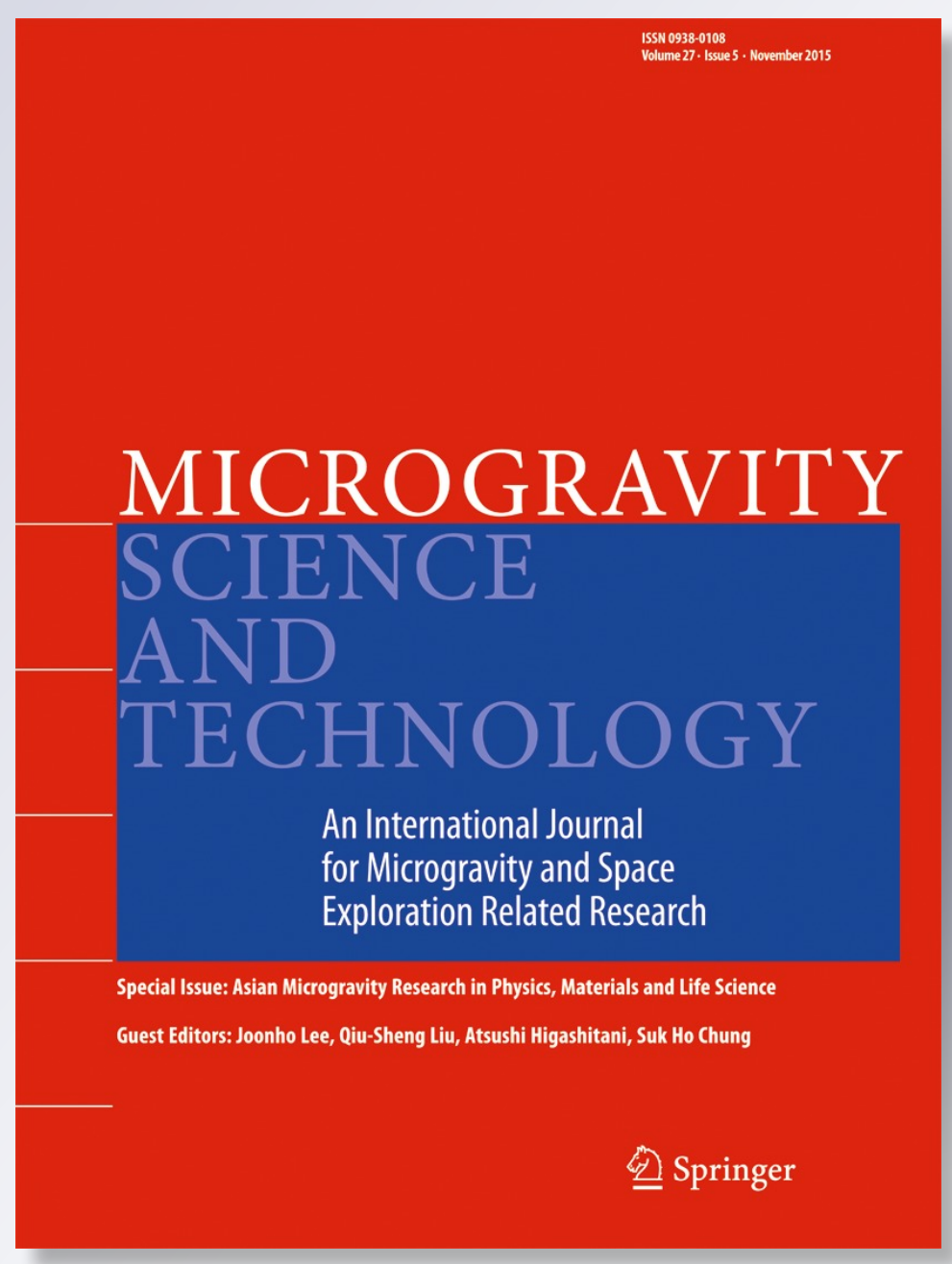

包 Springer 
Your article is protected by copyright and all rights are held exclusively by Springer Science +Business Media Dordrecht. This e-offprint is for personal use only and shall not be selfarchived in electronic repositories. If you wish to self-archive your article, please use the accepted manuscript version for posting on your own website. You may further deposit the accepted manuscript version in any repository, provided it is only made publicly available 12 months after official publication or later and provided acknowledgement is given to the original source of publication and a link is inserted to the published article on Springer's website. The link must be accompanied by the following text: "The final publication is available at link.springer.com". 


\title{
Opposed-flow Flame Spread Over Solid Fuels in Microgravity: the Effect of Confined Spaces
}

\author{
Shuangfeng Wang • Jun Hu • Yuan Xiao • Tan Ren • \\ Feng Zhu
}

Received: 13 November 2014 / Accepted: 19 February 2015 / Published online: 4 March 2015

(C) Springer Science+Business Media Dordrecht 2015

\begin{abstract}
Effects of confined spaces on flame spread over thin solid fuels in a low-speed opposing flow is investigated by combined use of microgravity experiments and computations. The flame behaviors are observed to depend strongly on the height of the flow tunnel. In particular, a non-monotonic trend of flame spread rate versus tunnel height is found, with the fastest flame occurring in the $3 \mathrm{~cm}$ high tunnel. The flame length and the total heat release rate from the flame also change with tunnel height, and a faster flame has a larger length and a higher heat release rate. The computation analyses indicate that a confined space modifies the flow around the spreading flame. The confinement restricts the thermal expansion and accelerates the flow in the streamwise direction. Above the flame, the flow deflects back from the tunnel wall. This inward flow pushes the flame towards the fuel surface, and increases oxygen transport into the flame. Such a flow modification explains the variations of flame spread rate and flame length with tunnel height. The present results suggest that the confinement effects on flame behavior in microgravity should be accounted to assess accurately the spacecraft fire hazard.
\end{abstract}

S. Wang $(\bowtie) \cdot$ Y. Xiao $\cdot$ F. Zhu

Key Laboratory of Microgravity, Institute of Mechanics, Chinese Academy of Sciences, Beijing 100190, China

e-mail: sfwang@imech.ac.cn

J. Hu $\cdot$ T. Ren

School of Aerospace Engineering, Beijing Institute of Technology,

Beijing 100081, China

Present Address:

Y. Xiao

College of Science Technology and Engineering, James Cook University, Townsville, QLD 4811, Australia
Keywords Flame spread · Solid fuel · Confined space · Microgravity

\section{Introduction}

In a microgravity environment, the essential elimination of buoyancy-induced flow makes it possible to study flames spreading over solid fuel surfaces in very low velocity flow. This type of flame spread is practically important since inhabited spacecrafts are designed to maintain a low velocity atmospheric circulation (of the order of $10 \mathrm{~cm} / \mathrm{s}$ ). Thus, the problem of flame spread in microgravity is of scientific interest and will improve our abilities to assess the fire safety aboard spacecraft.

A number of experimental studies have investigated flame spread over thermally thin solids in actual (e.g., Andracchio and Cochran 1976; Olson et al. 1988, 1991, 2001; Grayson et al. 1994; Ramachandra et al. 1995; Kashiwagi et al. 1996; Sacksteder et al. 1998) or simulated (Olson et al. 2009; Zhang and Yu 2011) microgravity conditions during the past decades. The primary variables considered so far included flow velocity, oxygen concentration, fuel thickness and width, and flow direction (opposing that of flame propagation, or in the same direction as that of propagation). In the same time, new two- and three-dimensional models were extensively developed (Frey and T'ien 1979; Bhattacharjee and Altenkirch 1990; Shih and T'ien 1997, 2000; Nakamura et al. 2002). A sustained effort has been made to incorporate thermal radiation which is particularly important for low-intensity flames. Over the years, there has been significant progress in understanding the mechanisms that control spreading flame behavior (T'ien et al. 2001).

Most previous studies on microgravity flame spread have been performed in relatively large areas, whereas a 
realistic fire could start and spread in constrained geometries (Friedman 1994, 2000). The available test section sizes for microgravity experiments, meanwhile, were rather limited, and the observations have been made in flow tunnels with varied dimensions, which implies that the influence of a confined space should be taken into account to interpret the experimental results. Only few studies have treated geometry effects on flame spread in microgravity. Using a two-dimensional numerical model, Shih and T'ien (1997) studied the behavior of concurrent flow flames spreading in a flow tunnel. In comparison with the flame spread in an infinite domain, the flame in a tunnel with a height $H=$ $10 \mathrm{~cm}$ has a faster spread rate and a longer length due to the aerodynamic flow channeling effect. As $H$ is reduced to $4 \mathrm{~cm}$, the flame length and the spread rate increase even further. Nevertheless, additional reduction in the tunnel height decreases the flame length and the spread rate due to heat loss to the walls. The same authors (Shih and T'ien 2000) constructed and numerically solved a model for concurrent flame spread in a three-dimensional flow tunnel. It was found that the three-dimensional effects are controlled by heat loss to the side walls when the flame is far away from the quenching limit. Near the quenching limit, however, sidewise oxygen diffusion becomes a dominant mechanism. Enclosure effects on opposed-flow flame spread were addressed numerically by Nakamura et al. (2002). Two cases were compared: an open configuration and a specific test chamber $(8.5 \mathrm{~cm}$ wide, $9.5 \mathrm{~cm}$ high, and $17.1 \mathrm{~cm}$ long). used in their microgravity experiments (Olson et al. 2001). The results showed that the flame spread rate for the enclosure case is faster than that for the open case, and the effects of the enclosure are most significant in the oxygen-controlled regime. Recently, Zhang and Yu (2011) performed experiments in a naturalconvection-suppressing narrow channel to study the influence of the channel width on opposed-flow flame spread rate. Near the quenching limits and the blow-off limits, the spread rate was shown to decrease with the increasing channel width. Although these studies demonstrate clearly the modifications of flame character in a confined space, the problem deserves more effort. In particular, quantitative effects of a finite size space on opposed-flow flame spread remain to be examined systematically considering the varied space dimensions. Additionally, the computational results need to be compared with experimental observations.

The focus of this study is to determine the effects of a confined space on microgravity flame spread and flame behaviors in a low-speed opposing air flow with the flow tunnel height as a parameter, and to understand the controlling mechanism. Drop-tower experiments are conducted to gather flame data for spread rate, flame length, and flame appearance for various tunnel heights. The observations, indicating notable variations of flame character as a function of the tunnel height, are compared with the numerical results which are based on a two-dimensional flame spread model. Simulations also examine the flow field in the tunnels and the heat release rate from the flame. The results are used to explain the observed flame behaviors in confined spaces.

\section{Experimental}

A series of microgravity experiments are conducted in the 3.6 s drop tower at the Key Laboratory of Microgravity, Chinese Academy of Sciences, Beijing. The gravity level during free fall is on the order of $10^{-3} \mathrm{~g}$. The experimental apparatus consists of a horizontal low-speed flow tunnel, a flow system, video cameras, and a control system. The flow tunnel is $30 \mathrm{~cm}$ long and $15 \mathrm{~cm}$ wide, while its height, $H$, can be adjusted in the range of 1.5 to $5 \mathrm{~cm}$. For the visualization purpose, the tunnel is made of quartz glass. The flow system supplies air flow from a high pressure gas bottle, and the flow rate is controlled by a mass flow controller (Alicat Scientific, type MC). The metered flow enters a plenum chamber and passes through honeycomb before entering the test tunnel. The flow passes through the tunnel at a velocity of $5 \mathrm{~cm} / \mathrm{s}$. The fuel used is a $0.062 \mathrm{~mm}$ thick laboratory wipe whose area density based upon the half thickness is $10.8 \mathrm{~g} / \mathrm{m}^{2}$. The small thermal inertia of the material enables steady-state results to be obtained in a short test time. The fuel sample is $5 \mathrm{~cm}$ wide by $14 \mathrm{~cm}$ long, and is held in the middle of the tunnel. An electrically heating wire is used to ignite the sample across the width at the downstream end of the sample. Ignition is achieved within $5 \mathrm{~s}$. Two color digital video cameras (Sony DCR-TRV900E) are used to capture the flame behaviors at 25 frames per second, one from the top of the test section and the other form the side.

The apparatus is installed inside a large enclosed capsule filled with air at one atmosphere pressure. For each test, the flow is initiated firstly. Then, after a time delay to allow the flow to fully develop, the fuel sample is ignited in normal gravity. As soon as a uniform flame front is established and the flame enters the view field of the cameras, the capsule is released. During the entire test procedure, the two cameras record the flame spread. The flame images are transferred into a computer for later analysis. For each tunnel, two or three microgravity tests are carried out. The data reported here are averaged results.

\section{Numerical Modeling}

A detailed description of the mathematical model for the flame spread over thin cellulosic solid has been given by 
Nakabe et al. (1994) and McGrattan et al. (1996). The gas phase is governed by conservation equations of mass, momentum, energy, and species (fuel gases and oxygen). Because the imposed flow velocity is low, the low Mach number approximation and the perfect gas law are applied. The gas-phase oxidation reaction is represented by a onestep, second-order, finite-rate Arrhenius reaction between fuel vapor and oxygen. Reaction parameters are identical to those used by Frey and T'ien (1979), and the thermal and transport properties are assumed to depend on temperature. The fuel is a cellulosic paper with chemical formula $\mathrm{C}_{6} \mathrm{H}_{10} \mathrm{O}_{5}$. The exothermic degradation of the solid is described by a pyrolysis reaction, a thermal oxidation reaction, and a char oxidation reaction. The reaction parameters and thermal properties are identical to those from Kashiwagi et al. (1992, 1996). Radiative loss from the solid is included in the model, but gas-phase radiation is neglected.

Top-view flame images from our experiments show a uniform flame front across the central portion of the sample width, and the flame reaches a steady spread rate rapidly after the drop. In view of these observations, a steady two-dimensional model appears reasonable for the modeling purpose and is used in the present study. The twodimensional flow tunnel is $30 \mathrm{~cm}$ long in the $x$ direction, but its height ( $y$ direction) is the parameter varied in the study. A forced air flow with a uniform velocity of $5 \mathrm{~cm} / \mathrm{s}$ is imposed at the tunnel entrance. The thin fuel is placed midway between the tunnel walls $(y=0)$. The $x=0$ position is fixed on the flame base which is $15 \mathrm{~cm}$ from the tunnel entrance, while the upstream end of the fuel is $8 \mathrm{~cm}$ from the entrance, which is the same as in the experiments. Because the flames are assumed to be symmetric, the computational domain is only a half-plane of the full tunnel. The temperature of the tunnel wall is assumed to be at room temperature. A uniform grid is used in the simulations, and the cell sizes are $0.2 \mathrm{~mm}$ and $0.075 \mathrm{~mm}$ in the $x$ direction and $y$ direction, respectively. The governing equations are solved numerically using finite difference techniques on the twodimensional computational mesh, and grid independence has been checked.

\section{Results and Discussion}

\section{Experimental Observations}

Just prior to the drop, a stable, uniform flame was established propagating over the fuel sample in normal gravity. The transition of the flame to a steady-state microgravity flame was completed within approximately $1 \mathrm{~s}$ from the drop start. After that, no further variations were detected in the apparent brightness, standoff distance, and leading edge region of the flame, while for some tests the trailing portion of the flame was growing slowly in the $3.6 \mathrm{~s}$ microgravity test time. The spreading flames after the normal- to micro-gravity transition are regarded as steady since opposed-flow flame spread is controlled mainly by processes in the flame leading edge.

Figure 1 shows side-view images of microgravity flames spreading in flow tunnels of different heights. In the most narrow tunnel $(H=1.5 \mathrm{~cm})$, the visible flame is very small. The brightest part of the flame is at or near the leading edge and the flame is almost entirely faint blue, indicating an absence of significant soot production. As the tunnel height increases slightly to $H=2 \mathrm{~cm}$, the length and luminance of the flame increase dramatically, with a bright yellow trail visible behind the blue leading edge. Near the trailing edge, the flame becomes dimmer and thinner, and a glow of soot is noted. The overall flame curves away from the fuel plane and then keeps nearly parallel with the fuel plane. When $H$ is increased to 2.5 and $3 \mathrm{~cm}$, the overall flame length increases further. However, a more significant change is observed to occur in the trailing portion of the flame, which curves back toward the fuel plane near the trailing

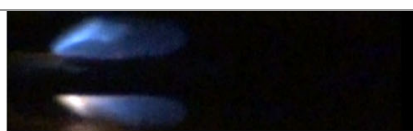

(a) $\mathrm{H}=1.5 \mathrm{~cm}$

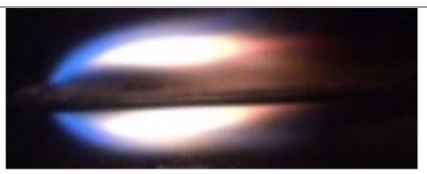

(b) $\mathrm{H}=2 \mathrm{~cm}$

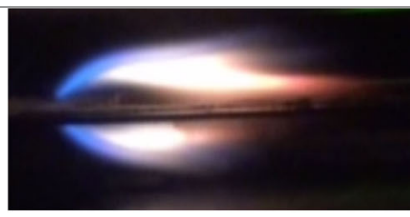

(c) $\mathrm{H}=2.5 \mathrm{~cm}$

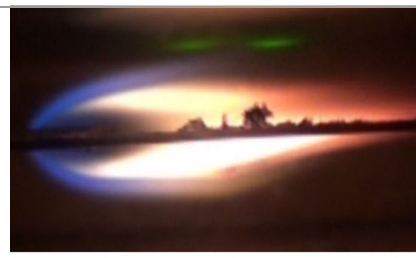

(d) $\mathrm{H}=3 \mathrm{~cm}$

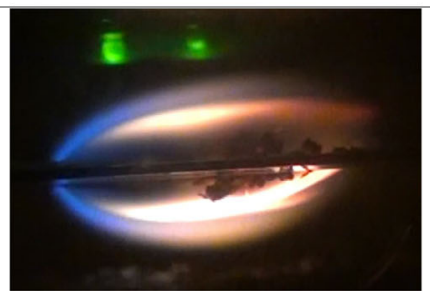

(e) $\mathrm{H}=3.5 \mathrm{~cm}$

Fig. 1 Images of steady microgravity flames spreading in flow tunnels of different heights (side view). All pictures are on the same scale, with the height equal to the corresponding tunnel height. The air flow enters from left at $5 \mathrm{~cm} / \mathrm{s}$ and $1 \mathrm{~atm}$ 
edge. In an even higher tunnel $(H=3.5$ and $4 \mathrm{~cm})$, the flame tail becomes nearly flat again, curving very slightly back towards the fuel plane near the trailing edge. There is evidence that the tunnel height reaches a critical value at approximately $3 \mathrm{~cm}$, beyond which the changes of the fame appearance are gradual and monotonic with increasing tunnel height. In fact, combustion tests have also been carried out in a $1 \mathrm{~cm}$ high tunnel. The flame extinguishes shortly after ignition, and a self-sustained spreading flame could not been achieved in the slow air flow of $5 \mathrm{~cm} / \mathrm{s}$ under microgravity conditions. In addition to heat loss, such a flame-spread limit may be caused by the limited oxygen supply into the tunnel. Since the objective of the study is to examine the effects of a confined space on flame spread, the results for such a case is not included here.

\section{Flame Spread Rate and Flame Length}

The flame spread rate is determined from the top-view video record of each test. By tracking the flame spread, relative position of the blue leading edge of the flame is obtained as a function of time. From the position-time data, flame spread rate can be derived. A steady spread rate is indicated by a linear variation of position with time.

A flame position versus time plot is shown in Fig. 2 for different tunnel heights. Prior to time zero, the flames spread in normal gravity at steady spread rates. Immediately following the drop at time zero, the flames slow down as a result of the transition from normal- to microgravity conditions. A linear position-time plot is restored at approximately $1 \mathrm{~s}$, after which a constant spread rate for the microgravity flame can be derived as the slope of the plot. In Fig. 3, measured flame spread rates in microgravity are given against tunnel heights. It is clear that the tunnel size has a significant influence on the magnitude of flame

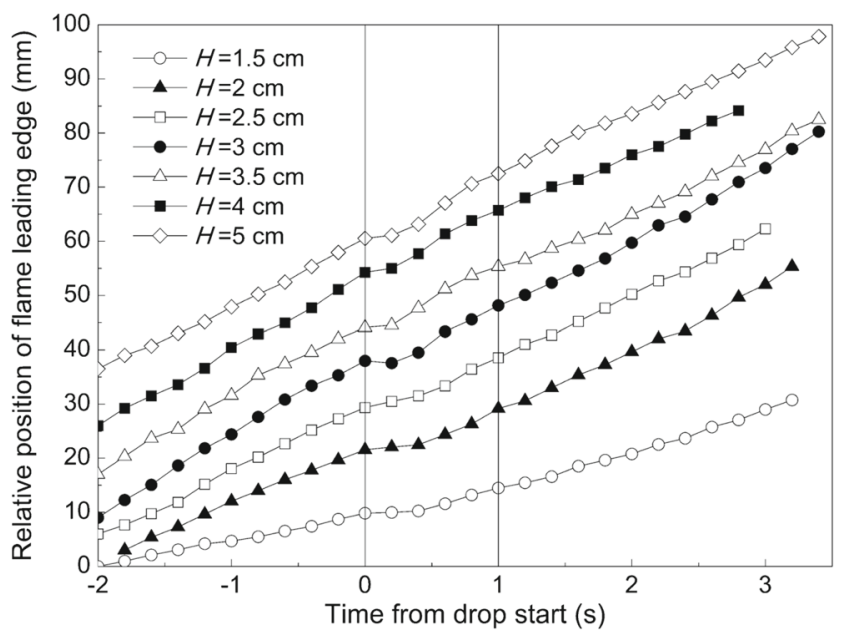

Fig. 2 Relative position of flame leading edge as a function of time for different tunnel heights

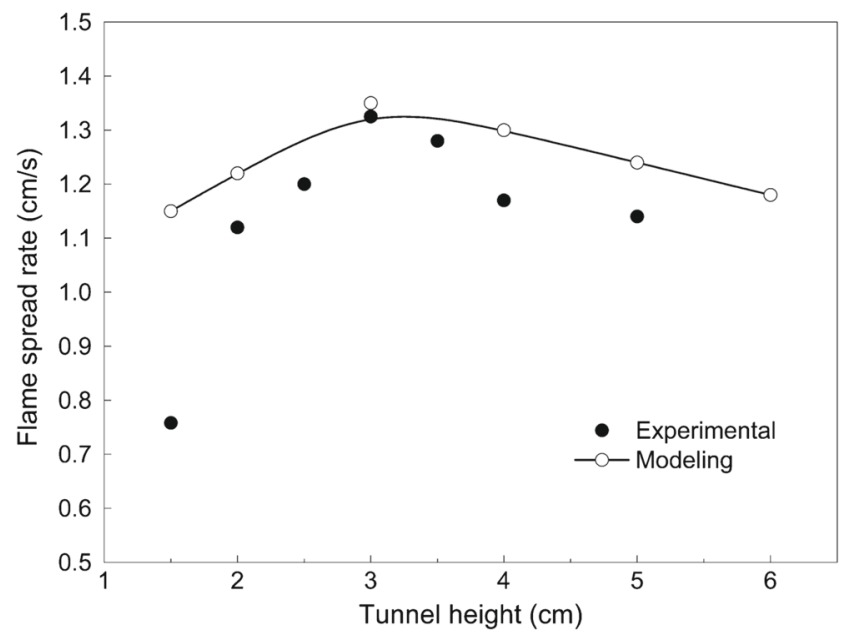

Fig. 3 Flame spread rate as a function of tunnel height

spread rate, and the spread rate curve is non-monotonic with respect to tunnel height, $H$. When $H$ is increased from 1.5 $\mathrm{cm}$, the spread rate increases until a maximum is reached at approximately $H=3 \mathrm{~cm}$. The flame spread is $75 \%$ faster in the $3 \mathrm{~cm}$ tunnel than in the $1.5 \mathrm{~cm}$ tunnel $(1.325$ $\mathrm{cm} / \mathrm{s}$ as against $0.758 \mathrm{~cm} / \mathrm{s})$. A reverse flame spread trend is observed when $H>3 \mathrm{~cm}$, i.e., the spread rate decreases with increasing tunnel height. In this regime, an interesting observation is that an invariable spread rate may be approached in a flow tunnel with large height since the spread rate seems to decrease asymptotically with $H$. Flame spread rates in a $20 \mathrm{~cm}$ diameter tunnel have been measured by Olson (1991) for a cellulosic paper whose area density is similar to that of the present fuel $\left(10 \mathrm{~g} / \mathrm{m}^{2}\right.$ compared with $10.8 \mathrm{~g} / \mathrm{m}^{2}$ for the present case). In an air flow of $5 \mathrm{~cm} / \mathrm{s}$, the spread rate was determined to be $1.08 \mathrm{~cm} / \mathrm{s}$, comparable to the present test value of $1.14 \mathrm{~cm} / \mathrm{s}$ which is obtained at $H=$ $5 \mathrm{~cm}$. It implies that the confinement effects on flame spread

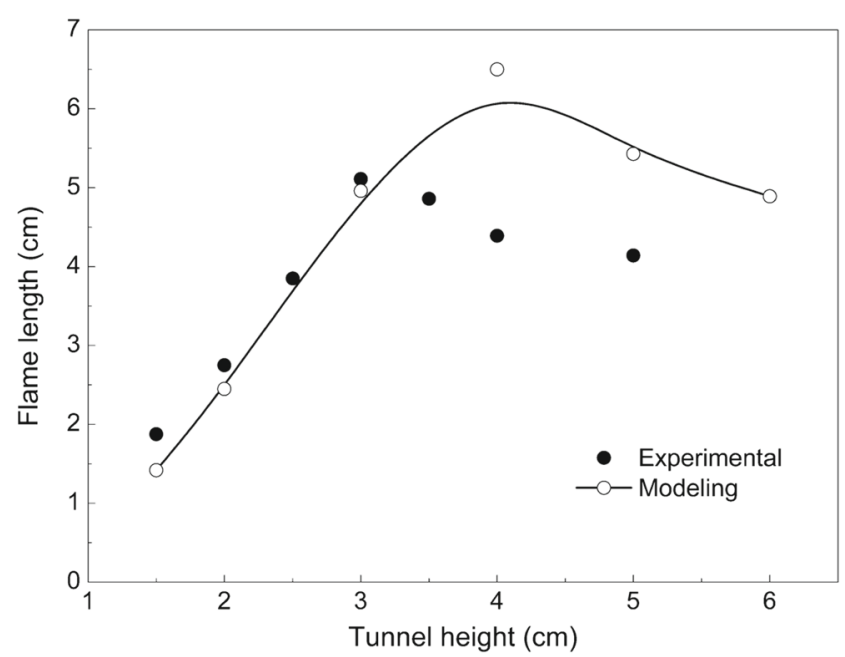

Fig. 4 Flame length as a function of tunnel height 

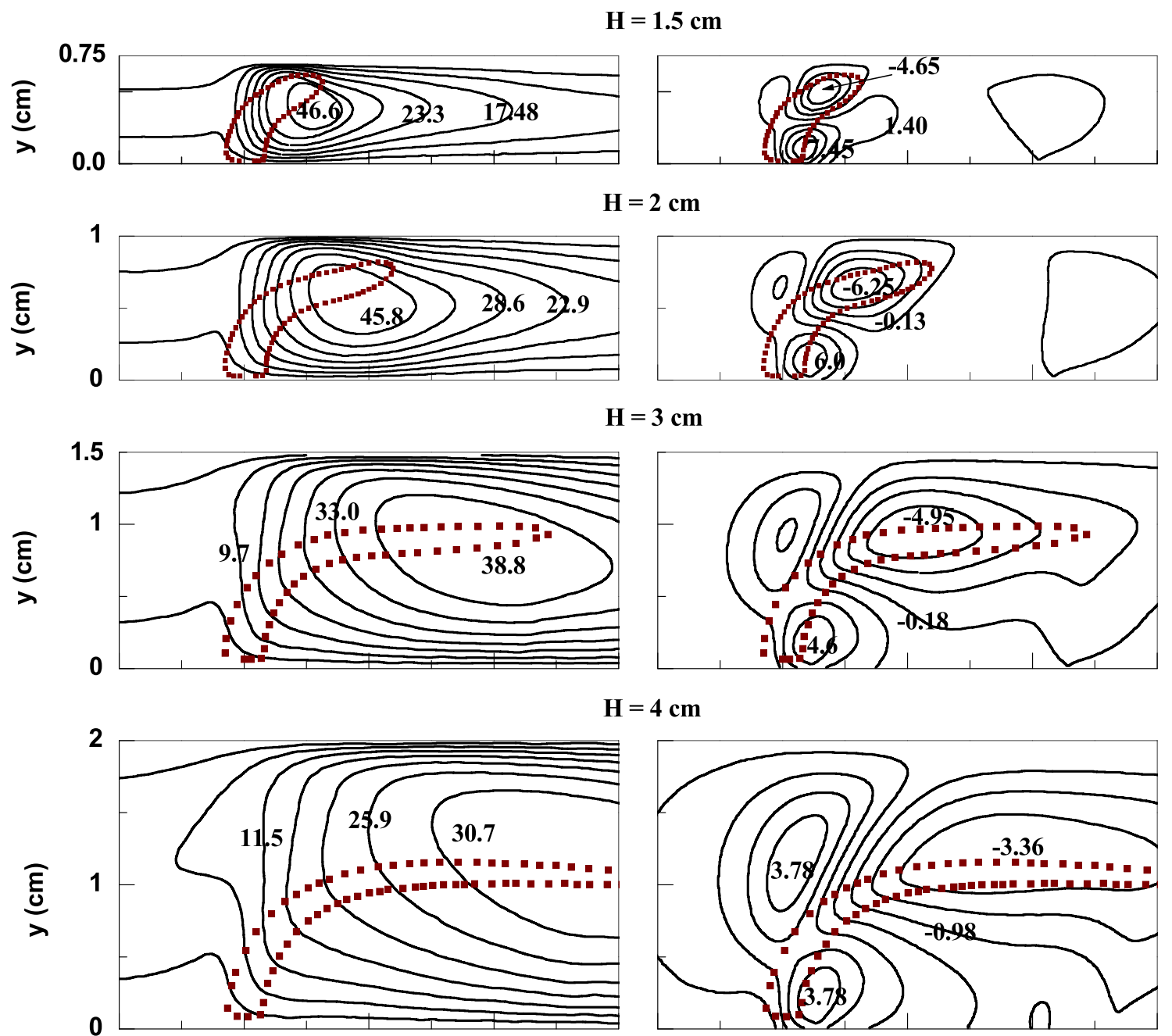

$\mathrm{H}=\mathbf{4} \mathrm{cm}$

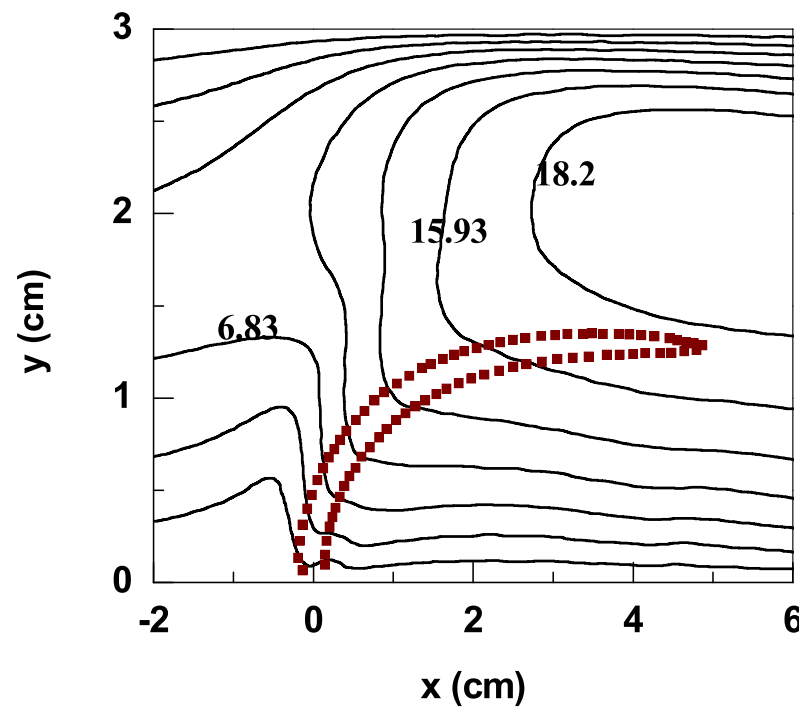

$\mathrm{H}=6 \mathrm{~cm}$
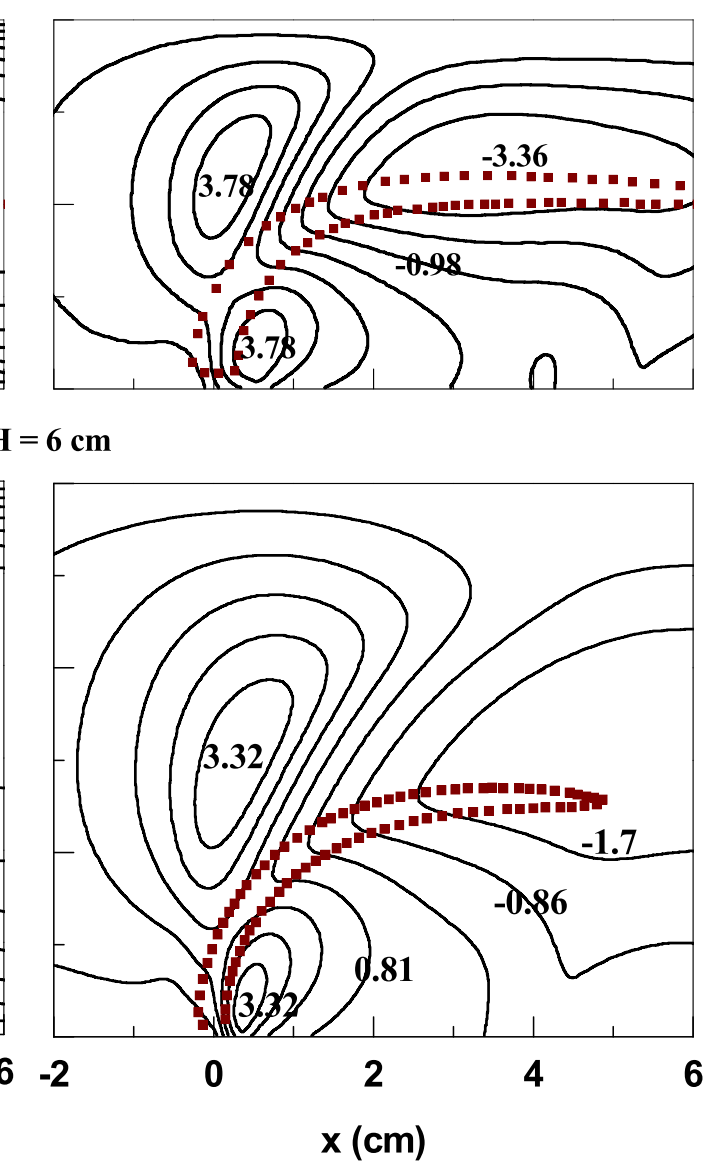

Fig. 5 Flow velocity contours (in $\mathrm{cm} / \mathrm{s}$ ) around the flame (depicted by reaction rate of $\left.10^{-4} \mathrm{~g} /\left(\mathrm{cm}^{3} \mathrm{~s}\right)\right)$ for different tunnel heights. Left column: velocity component in the streamwise direction ( $x$ direction);

Right column: velocity component in the direction perpendicular to the incoming flow ( $y$ direction) 

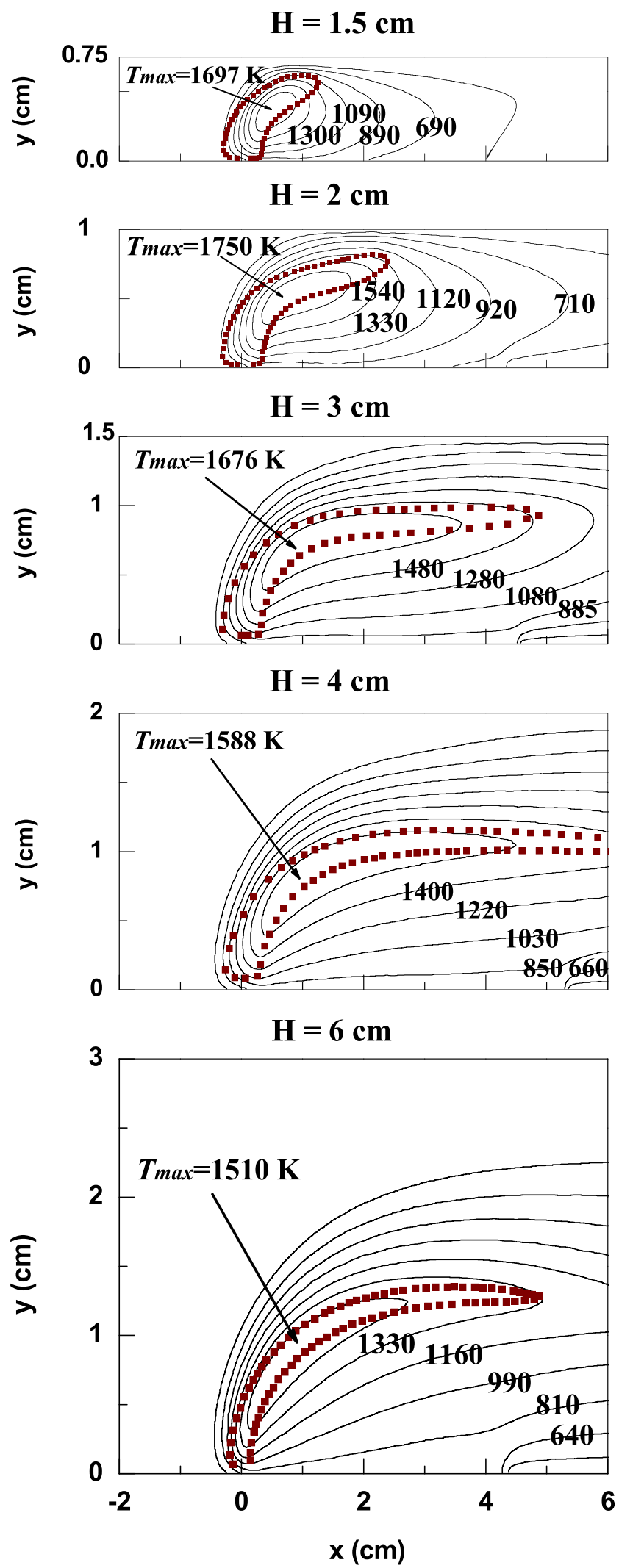

Fig. 6 Temperature contours around the flame (depicted by reaction rate of $\left.10^{-4} \mathrm{~g} /\left(\mathrm{cm}^{3} \mathrm{~s}\right)\right)$ for different tunnel heights become less important when the test tunnel is relatively large. Also shown in Fig. 3 are the numerical predictions of flame spread rate. Compared with experiments, the computations produce higher spread rates especially in the low range of $H$. The non-monotonic trend of flame spread rate vs. tunnel height, however, is well captured.

The overall flame length is measured from the side-view flame images. Although the flame shapes in some of the microgravity tests do not reach a complete steady-state, the variations of flame length are very slow, and representative values could be obtained after $1 \mathrm{~s}$ from the drop. Actually, the data presented here have been collected at the same time of $2 \mathrm{~s}$. As for the numerical modeling, following Shih and T'ien (1997), the visible flame boundary is defined by the contour of a gas phase reaction rate of $10^{-4} \mathrm{~g} /\left(\mathrm{cm}^{3} \mathrm{~s}\right)$, and a constant flame length is determined for each tunnel height. Both sets of flame length results are given as a function of the tunnel height in Fig. 4. It is readily seen that the flame length strongly depends on tunnel size. The entire flame length curve is clearly non-monotonic with tunnel height, while a maximum value occurs at approximately $H=3$ and $4 \mathrm{~cm}$ from the experiments and computations, respectively.

\section{Flow Field around the Flame}

Figure 5 presents the computed flow velocity contours around the spreading flame for five different tunnels. The visible flame boundary is also depicted. Since there is thermal expansion near the flame and the expansion is constrained in the direction perpendicular to incoming flow ( $y$ direction), the streamwise flow (in the $x$ direction) is accelerated towards the downstream region. This flow acceleration effect is observed in all the tunnels studied. But it

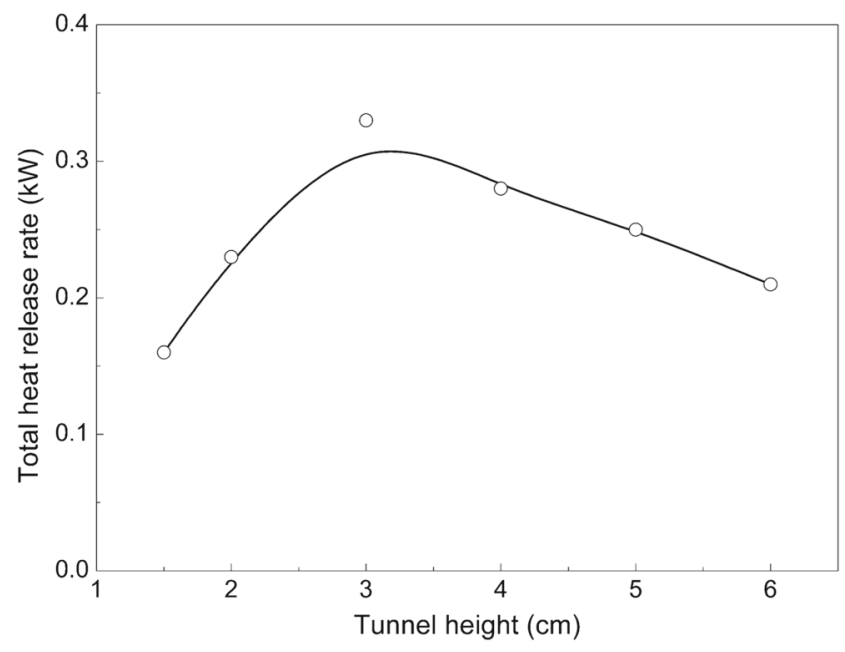

Fig. 7 Total heat release rate as a function of tunnel height 
is most pronounced in intermediate-height tunnels $(H \approx 3$ $4 \mathrm{~cm}$ ) because the degree of the acceleration depends on both the flame size and the tunnel dimension. Note that the larger downstream velocity produces a longer flame. Thus, the trend of flow acceleration behind the flame is consistent with the non-monotonic variation of flame length with tunnel height.

With the velocity component in the $y$ direction, there is an additional observation about the confinement influence. At the leading edge of the flame, the flow is directed outwards due to the blowing of pyrolysis gases from the fuel. Above the flame, however, the flow deflects back from the tunnel wall. This inward flow pushes the flame towards the fuel surface, and transports more oxygen into the flame (compared with the no inward flow case which is assumed to happen in a large tunnel). Because of the enhanced combustion reaction in the flame, the heat flux from the flame to the fuel is increased, so the flame spread becomes faster. Once again, such a flow trend is most pronounced in intermediateheight tunnels, explaining the trend of flame spread rate with tunnel height.

\section{Flame Temperature and Heat Release Rate}

The flow modification discussed above changes the temperature distribution around the flame, as shown in Fig. 6. The highest temperature is in the middle portion of the flame. Its value reduces when the tunnel height decreases or increases from $2 \mathrm{~cm}$, with a peak occurring near $H=2 \mathrm{~cm}$.

As the flame spread rate is concerned, heat release rate from the flame is a more relevant parameter since the former depends on the latter directly (Quintiere, 2001). In Fig. 7, the computed result for the total heat release rate is given as a function of the tunnel height. It is clearly shown that the tunnel size has a significant influence on the chemical energy release. The total heat release rate is highest in the $3 \mathrm{~cm}$ high tunnel, and it decreases in narrower or higher tunnels. Thus, a non-monotonic trend of heat release rate vs. tunnel height is obtained. This trend can satisfactorily explain the variation of the flame spread rate with tunnel height, although it should be regarded as a result of the flow modification in confined spaces.

\section{Conclusions}

Drop-tower experiments and numerical computations are performed to investigate the flame spread over thin solids in opposed air flow. To examine the effect of a confined space, the flow tunnel has a variable height in a range of 1.5 to 5 $\mathrm{cm}$ (in experiments) or $6 \mathrm{~cm}$ (in computations), while the velocity of the imposed flow is fixed at $5 \mathrm{~cm} / \mathrm{s}$. Thin cellulosic paper is used as the solid fuel. The major conclusions are as follows:

(1) The tunnel height has significant influence on flame behaviors in the low flow velocity regime. With tunnel heights greater than $3 \mathrm{~cm}$, decreasing tunnel height increases the flame spread rate. This is opposite to the flame spread trend in more narrow tunnels, i.e., flame spread rate decreases with decreasing tunnel height. Thus, the flame spread rate curve is non-monotonic with respect to tunnel height. The flame length also depends on tunnel height and the faster flame has a larger length.

(2) A confined space restricts the thermal expansion and accelerates the flow in the streamwise direction. Above the flame, the flow deflects back from the tunnel wall. This inward flow pushes the flame towards the fuel surface, and increases oxygen transport into the flame. The flow modification may explain the trends of flame spread rate and flame length with tunnel height.

(3) The flow modification changes heat release rate from the flame. The total heat release rate reaches a maximum in the $3 \mathrm{~cm}$ tunnel and decreases as the tunnel height decreases or increases.

(4) Flame spread in a narrow space is an important fire safety challenge in microgravity conditions. The confinement effects should be taken into account to assess accurately the fire hazard aboard spacecraft.

Acknowledgments This work is funded by the Strategic Pioneer Program on Space Science, Chinese Academy of Sciences, under grant No. XDA04020410.

\section{References}

Andracchio, C.R., Cochran, T.H.: Gravity effects on flame spreading over solid surfaces. NASA TN D-8228 (1976)

Bhattacharjee, S., Altenkirch, R.A.: Radiation-controlled, opposedflow flame spread in a microgravity environment. Proc. Combust. Inst. 23, 1627-1633 (1990)

Frey, A.E., T'ien, J.S.: A theory of flame spread over a solid fuel including finite-rate chemical kinetics. Combust. Flame 36, 263289 (1979)

Friedman, R.: Risks and issues in fire safety on the space station. NASA TM-106430 (1994)

Friedman, R.: Testing and selection of fire-resistant materials for spacecraft use. NASA TM-209773 (2000)

Grayson, G., Sacksteder, K.R., Ferkul, P.V., T'ien, J.S.: Flame spreading over a thin solid in low-speed concurrent flow-drop tower experimental results and comparison with theory. Microgravity Sci. Technol. 7, 187-195 (1994)

Kashiwagi, T., Nambu, H.: Global kinetic constants for thermal oxidative degradation of a cellulosic paper. Combust. Flame 88, 345368 (1992)

Kashiwagi, T., McGrattan, K.B., Olson, S.L., Fujita, O., Kikuchi, M., Ito, K.: Effects of slow wind on localized radiative ignition and 
transition to flame spread in microgravity. Proc. Combust. Inst. 26, 1345-1352 (1996)

McGrattan, K.B., Kashiwagi, T., Baum, H.R., Olson, S.L.: Effects of ignition and wind on the transition to flame spread in a microgravity environment. Combust. Flame 106, 377-391 (1996)

Nakabe, K., McGrattan, K.B., Kashiwagi, T., Baum, H.R., Yamashita, H., Kushida, G.: Ignition and transition to flame spread over a thermally thin cellulosic sheet in a microgravity environment, Combust. Flame 98, 361-374 (1994)

Nakamura, Y., Kashiwagi, T., McGrattan, K.B., Baum, H.R.: Enclosure effects on flame spread over solid fuels in microgravity. Combust. Flame 130, 307-321 (2002)

Olson, S.L., Ferkul, P.V., T'ien, J.S.: Near-limit flame spread over a thin solid fuel in microgravity. Proc. Combust. Inst. 22, 1213-1222 (1988)

Olson, S.L.: Mechanisms of microgravity flame spread over a thin solid fuel: oxygen and opposed flow effects. Combust. Sci. Tech. 76, 233-249 (1991)

Olson, S.L., Kashiwagi, T., Fujita, O., Kikuchi, M., Ito, K.: Experimental observations of spot radiative ignition and subsequent three-dimensional flame spread over thin cellulose fuels. Combust. Flame 125, 852-864 (2001)

Olson, S.L., Miller, F.J., Jahangirian, S., Wichman, I.S.: Flame spread over thin fuels in actual and simulated microgravity conditions. Combust. Flame 156, 1214-1226 (2009)
Quintiere, J.G.: Fundamentals of Fire Phenomena. Wiley, West Sussex, England (2001)

Ramachandra, P.A., Altenkirch, R.A., Bhattacharjee, S., Tang, L., Sacksteder, K., Wolverton, M.K.: The behavior of flames spreading over thin solids in microgravity. Combust. Flame 100, 71-84 (1995)

Sacksteder, K.R., Greenberg, P.S., Pettegrew, R.D., T'ien, J.S., Ferkul, P.V., Shih, H.-Y.: Forced flow flame spreading test: preliminary findings from the USMP-3 Shuttle mission. Third United States Microgravity Payload: One Year Report. NASA/CP-1998- 207891 (1998)

Shih, H.-Y., T'ien, J.S.: Modeling wall influence on solid-fuel flame spread in a flow tunnel. AIAA paper 97-0236 (1997)

Shih, H.-Y., T'ien, J.S.: Modeling concurrent flame spread over a thin solid in a low-speed flow tunnel. Proc. Combust. Inst. 28, 2777 2784 (2000)

T'ien, J.S., Shih, H.-Y., Jiang, C.-B., Ross, H.D., Miller, F.J., Fernandez-Pello, A.C., Torero, J.L., Walther, D.: Mechanisms of flame spread and smolder wave propagation. In: Ross, H.D. (ed.) Microgravity Combustion: Fire in Free Fall. Academic Press, San Diego (2001)

Zhang, X., Yu, Y.: Experimental studies on the threedimensional effects of opposed-flow flame spread over thin solid materials. Combust. Flame 158, 1193-1200 (2011) 